http://ejournal.stkip-pgri-sumbar.ac.id/index.php/horizon

\title{
PENGARUH INTELEGENCE QUOTIENT (IQ), MINAT, KOMUNIKASI ORANG TUA, DAN TEMAN SEBAYA TERHADAP KEPUTUSAN SISWA MEMILIH JURUSAN DI SMA N 1 SUNGAI RUMBAI
}

\author{
Riko Saputra, Mona Amelia, Putri Meliza Sari \\ Program Studi Pendidikan Ekonomi STKIP PGRI Sumatera Barat \\ rikosaputra@gmail.com
}

\begin{abstract}
The study found that: First, intelligence (IQ) (X1) has a significant effect on students' decisions to choose majors with a regression coefficient of 0.496 . This coefficient value is significant because the value of $t$ count $5.792 \geq \mathrm{t}$ table 1.65622 means that intelligence (IQ) increases by one unit. then the student's decision to choose a major also increased by 0.496 . Both interests (X2) have a significant effect on students' decisions to choose majors with a regression coefficient of 0.367 . This coefficient value is significant because the value of $t$ count $10,533 \geq t$ table 1.66571 means that if the interest increases by one unit. then the student's decision to choose a major also increased by 0.367 . The third parent communication (X3) has a significant effect on student learning outcomes at SMAN 1 Sungai Rumbai with a regression coefficient of 0.309 . This coefficient value is significant because the $t$ value is 5.446 $\geq \mathrm{t}$ table 1.65622 , meaning that parental communication increases by one unit. it will increase the student's decision to choose a major by 1.073. The four peers (X4) have a significant effect on the student's decision to choose a major with a regression coefficient of 0.309 . This coefficient value is significant because the $t$ value is 4.300 $\geq \mathrm{t}$ table 1.65622 , it means that if peers increase by one unit. it will increase the student's decision to choose a major by 0.309. The five Intelligence (IQ), Interests, Parents Communication, and Peers simultaneously have a significant influence on students' decisions to choose majors at SMAN 1 Sungai Rumbai with Fcount 51.641 $\geq$ Ftable 2.28 and significant $0.000<0.05$. It is recommended that teachers, schools and parents pay more attention to or control student learning activities at school and at home so that students do not make the wrong decision to continue the educational process
\end{abstract}

Keywords: Intelegence, Interest, Communication, Schoolmate, Decision

PEDAHULUAN

Di dalam pendidikan nasional terdapat program wajib belajar pendidikan dasar 12 tahun, yang mencakup

Sekolah Dasar dan Madrasah, serta SMP, SMP terbuka, MTs dan pendidikan non 
http://ejournal.stkip-pgri-sumbar.ac.id/index.php/horizon

formal kesetaraan SMP. Setelah menempuh pendidikan dasar sembilan tahun tersebut diharapkan para lulusan pendidikan dasar sembilan tahun dapat melanjutkan ke jenjang sekolah yang lebih tinggi yaitu pada program pendidikan menengah, agar kualitas sumber daya manusia Indonesia dapat berkualitas sehingga mampu bersaing dalam era globalisasi sekarang ini yang penuh dengan persaingan. Program pendidikan tingkat satuan menengah di Indonesia ada beberapa jenis antara lain SMA, SMK, MA, MAK, atau bentuk lain yang sederajat.

Salah satu program pendidikan tingkat sekolah menengah adalah Sekolah Menengah Atas (SMA). Pada SMA mempunyai pembelajaran untuk membekali peserta didik dengan keterampilan-keterampilan tertentu yang nantinya dapat diaplikasikan dalam kehidupan sehari-hari. Pendidikan kejuruan merupakan pendidikan yang mengarahkan peserta didik untuk bekerja pada bidang tertentu (UUSPN 2, 1989). Pendidikan Kejuruan adalah pendidikan pada jenjang menengah yang mengutamakan pengembangan kemampuan siswa untuk melaksanakan jenis pekerjaan tertentu (PP 29 tahun 1990 Pasal 1 ayat 3 ).

Melanjutkan sekolah ke SMA merupakan pilihan yang baik, siswa yang melanjutkan ke SMA dihadapkan pada pemilihan penjurusan saat mereka mendaftar ke SMA dengan pilihan jurusan beragam, yang seringkali membuat mereka sedikit sulit untuk memilih. Dalam memilih jurusan, siswa perlu memperhitungakan beberapa faktor seperti kemampuan, minat, bakat, kepribadian, dll. Salah memilih jurusan punya dampak yang signifikan terhadap kehidupan anak di masa mendatang. Sering dijumpai siswa SMA yang merasa tidak cocok dengan jurusan yang dimasuki. Dampak dalam salah memilih jurusan antara lain dari segi masalah psikologis, masalah akademik dan masalah relasional 
Keefektifan pemilihan jurusan di SMAN 1 Sungai Rumbai Dapat Dilihat dari Nilai ujian nasional yang diperoleh oleh peserta didik yang telah menempuh ujian nasional di SMAN Sungai Rumbai adapun datanya sebagai berikut

Dari tabel dibawah dapat dilihat keseluruhan nilai UN SMA di Kabupaten Dharmasraya. Pada penelitian ini yang penulis jadikan tempat penelitian adalah SMAN 1 Sungai Rumbai pada kelas $\mathrm{X}$. Alasan peneliti mengambil tempat tersebut adalah SMA Negeri 1 Sungai Rumbai merupakan SMA baru yang belum lama diresmikan dan sudah mempunyai akreditas A, di SMA Negeri 1 Sungai Rumbai ini

Tabel 1. Daftar Peringkat Sekolah SMA Negeri di Kabupaten Dharmasraya Berdasarkan Jumlah Nilai Ujian Nasional SMA Tahan Pelajaran 2018/2019

\begin{tabular}{clcccc}
\hline No & \multicolumn{1}{c}{ Nama Sekolah } & Akreditasi & $\begin{array}{c}\text { Jumlah } \\
\text { Peserta }\end{array}$ & $\begin{array}{c}\text { Nilai } \\
\text { Ujian UN }\end{array}$ & $\begin{array}{c}\text { Rang } \\
\text { king }\end{array}$ \\
\hline 1 & SMAN 1 SITIUNG & A & 157 & 52,58 & 1 \\
2 & SMAN 1 KOTO BARU & A & 115 & 48,5 & 5 \\
3 & SMAN 1 PULAU PUNJUNG & A & 122 & 50,12 & 3 \\
4 & SMAN 1 SUNGAI RUMBAI & A & 101 & 44,31 & 8 \\
5 & SMAN 2 PULAU PUNJUNG & A & 84 & 43,42 & 10 \\
6 & SMAN 1 TIMPEH & A & 65 & 47,02 & 6 \\
7 & SMAN 2 KOTO BARU & A & 62 & 49,04 & 4 \\
8 & SMAN 1 KOTO BESAR & A & 21 & 44,6 & 9
\end{tabular}


Vol. 1 No. 2 (Mei 2021) (284-293)

http://ejournal.stkip-pgri-sumbar.ac.id/index.php/horizon

$\begin{array}{clcccc}9 & \text { SMAN 1 IX KOTO } & \text { A } & 21 & 40,88 & 13 \\ 10 & \text { SMAN 1 KOTO SALAK } & \text { A } & 63 & 47,01 & 7 \\ 11 & \text { SMAN UNGGUL DHARMASRAYA } & \text { A } & 14 & 51,81 & 2 \\ 12 & \text { SMAN 1 ASAM JUJUHAN } & \text { A } & 23 & 37,75 & 14 \\ 13 & \text { SMAN 1 TIUMANG } & \text { A } & 27 & 41,11 & 12 \\ 14 & \text { SMAN 2 SUNGAI RUMBAI } & \text { A } & 19 & 42,26 & 11 \\ & \text { RATA-RATA } & & 897 & 47,67 & \end{array}$

Sumber : Dinas Koperasi, Perindustrian dan Perdagangan Provinsi Sumatera Barat, 2019

Berdasarkan tabel diatas terlihat bahwa hasil ujian nasional SMAN 1 Sungai Rumbai berada pada posisi ke 14 dimana itu merupakan posisi terakhir dari semua SMA yang ada di Dhamasraya yang memiliki akreditasi A oleh sebab itu peneliti tertarik untuk mengetahui adakah pengaruh dari pemilihan jurusan terhadap hasil belajar yang didapat oleh siswa di SMAN 1 Sungai Rumbai

\section{METODE PENELITIAN}

Pada penelitian ini sesuai dengan rumusan masalah dan batasan masalah serta tujuan penelitian, penelitian ini tergolong penelitian asosiatif, Penelitian yang dilakukan merupakan penelitian yang bersifat asosiatif. Sugiyono (2012), penelitian asosiatif adalah penelitian yang bertujuan untuk menemukan ada atau tidaknya hubungan atau pengaruh antara variabel yang satu dengan variabel lainnya.

Populasi dalam penelitian ini adalah Siswa Kelas X SMAN 1 Sungai Rumbai yang berjumlah 140 orang Teknik pengambilan sampel dalam pene adalah cluster sampling. sampel berkelompok atau merupakan cluster sampling digunakan pada saat data sampel lebih layak untuk dibuat secara berkelompok dari pada secara individu. Untuk itu pengertian cluster dapat disebut sebagai suatu Negara yang didalamnya terdapat provinsi dan kabupaten. Pada skala yang lebih kecil, cluster dapat digunakan dalam kelompok kelas atau grup. Teknik ini digunakan untuk 
mengantisipasi peneliti untuk validitas angket. Suatu skala pengukuran

memilih sampel secara random dan membagikannya dalam kelas atau kelompok. Dalam penelitian ini cluster yang dipilih adalah Kelas $\mathrm{X}$ IPS dan Kelas $\mathrm{X}$ IPS SMAN 1 Sunggai Rumbai.

Menurut Arikunto (2010), "angket atau kuesioner adalah sejumlah pertanyaan tertulis yang digunakan untuk memperoleh imformasi dari reponden dalam arti tentang laporan pribadinya atau halhal yang ia ketahui.

Sebelum angket diedarkan kepada responden, terlebih dahulu dilakukan uji coba. Uji coba ini digunakan untuk mengetahui dikatakan valid bila ia melakukan apa yang seharusnya dilakukan dan mengukur apa yang seharusnya di ukur Arikunto (2010:211) sebuah angket dikatakan valid apabila dapat mengungkapkan kata dari variabel yang diteliti secara tepat. Pernyataan dikatakan valid Jika $r$ hitung $\geq r$ tabel 0,361 dengan taraf signifikan 0,361. Menurut Nunally dalam Ghozali (2011:48) suatu konstruk atau variabel dikatakan reliable jika memberikan nilai Cronbach Alpha> 0,70. Untuk mengukur reliabilitas dari suatu instrumen dalam penelitian ini, peneliti melihat nilai Cronbach alpha dengan menggunakan bantuan program SPSS Versi 16.0.

Tabel 2. Hasil Pengujian Reliabilitas

\begin{tabular}{l|c|c|c|}
\hline \multicolumn{1}{|c|}{ Variabel } & Jumlah item & Cronbach alpha & Kesimpulan \\
Keputusan Siswa & 15 & 0,920 & Reliabel \\
Intelegence Quotient & 12 & 0,890 & Reliabel \\
Minat & 15 & 0,931 & Reliabel \\
Komunikasi Orang Tua & 15 & 0,904 & Reliabel \\
Teman Sebaya & 9 & 0,898 & Reliabel \\
\hline
\end{tabular}
rata pada variabel Keputusan Siswa adalah

\section{HASIL DAN PEMBAHASAN}

Berdasarkan TCR dari masing-masing variabel bahwa rata- sebesar 4,10 pada TCR sebesar 81,20 tergolong pada kategori baik, untuk ratarata variabel Intelegence quotient adalah 
Vol. 1 No. 2 (Mei 2021) (284-293)

http://ejournal.stkip-pgri-sumbar.ac.id/index.php/horizon

sebesar 4,30 pada TCR sebesar 85,99 sebesar 4,16 pada TCR sebesar 83,30 tergolong pada kategori cukup. untuk tergolong pada kategori baik. untuk ratarata-rata variabel minat adalah rata variabel teman sebaya adalah sebesar sebesar 4,36 pada TCR sebesar 87,28 4,20 pada tcr sebesar 84,58 tergolong pada tergolong pada kategori baik, untuk kategori baik.

variabel komunikasi orang tua adalah

Koefisien Determinasi $\left(\mathrm{R}^{2}\right)$

Tabel 3. Koefisien Determinasi $\left(\mathrm{R}^{2}\right)$

\begin{tabular}{|c|c|c|c|c|}
\hline Model & $\mathrm{R}$ & $\mathrm{R}$ Square & $\begin{array}{c}\text { Adjusted R } \\
\text { Square }\end{array}$ & $\begin{array}{c}\text { Std. Error of the } \\
\text { Estimate }\end{array}$ \\
\hline 1 & $0,778^{\mathrm{a}}$ & 0,605 & 0,593 & 6,27032 \\
\hline
\end{tabular}

Berdasarkan hasil pada tabel (keputusan siswa) dapat dijelaskan oleh

di atas hasil pengelolaan data yang variabel independen (intelegence quotient, tepat dilihat pada tabel model minat, komunikasi orang tua dan teman summary diperoleh hasil $\mathrm{R}$ squere sebaya) sedangkan sisanya sebesar 39,5\% sebesar 0,605 yang artinya 60,5\% dipengaruhi oleh variabel lain yang tidak perubahan pada variabel dependen termasuk dalam penelitian ini.

\section{Hasil Uji T}

Tabel. 4 Hasil Uji T

\section{Coefficients $^{\mathrm{a}}$}

\begin{tabular}{|c|c|c|c|c|c|c|}
\hline \multirow[b]{2}{*}{ Mode } & & \multicolumn{2}{|c|}{$\begin{array}{l}\text { Unstandardized } \\
\text { Coefficients }\end{array}$} & \multicolumn{3}{|l|}{$\begin{array}{l}\text { Standardized } \\
\text { Coefficients }\end{array}$} \\
\hline & & $\mathrm{B}$ & Std. Error & Beta & $\mathrm{t}$ & Sig. \\
\hline 1 & (Constant) & -19.071 & 5.337 & & -3.574 & .000 \\
\hline & $\mathrm{X} 1$ & .496 & .086 & .325 & 5.792 & .000 \\
\hline & $\mathrm{X} 2$ & .367 & .035 & .585 & 10.533 & .000 \\
\hline & X3 & .309 & .057 & .302 & 5.446 & .000 \\
\hline & $\mathrm{X} 4$ & .309 & .072 & .236 & 4.300 & .000 \\
\hline
\end{tabular}


Vol. 1 No. 2 (Mei 2021) (284-293)

http://ejournal.stkip-pgri-sumbar.ac.id/index.php/horizon

\section{Coefficients $^{\mathrm{a}}$}

\begin{tabular}{|c|c|c|c|c|c|c|}
\hline \multirow[b]{2}{*}{ Model } & & \multicolumn{2}{|c|}{$\begin{array}{l}\text { Unstandardized } \\
\text { Coefficients }\end{array}$} & \multicolumn{3}{|l|}{$\begin{array}{l}\text { Standardized } \\
\text { Coefficients }\end{array}$} \\
\hline & & B & Std. Error & Beta & $\mathrm{t}$ & Sig. \\
\hline 1 & (Constant) & -19.071 & 5.337 & & -3.574 & .000 \\
\hline & $\mathrm{X} 1$ & .496 & .086 & .325 & 5.792 & .000 \\
\hline & $\mathrm{X} 2$ & .367 & .035 & .585 & 10.533 & .000 \\
\hline & $\mathrm{X} 3$ & .309 & .057 & .302 & 5.446 & .000 \\
\hline & $\mathrm{X} 4$ & .309 & .072 & .236 & 4.300 & .000 \\
\hline
\end{tabular}

a. Dependent Variable: $\mathrm{Y}$

Pengaruh masing-masing variabel bebas secara individu kepada variabel terikat:

Untuk variabel intelegence quotient diperoleh nilai $\mathrm{t}$ hitung sebesar $5,792 \geq \mathrm{t}_{\text {tabel }}$ sebesar 1,65622 dengan nilai signifikan $0,000 .<0,05$ berarti $\mathrm{H}_{0}$ diterima $\mathrm{H}_{1} \quad$ ditolak dengan demikian dapat dikatakan bahwa terdapat pengaruh yang signifikan Intelegence Quotient (IQ) terhadap keputusan siswa memilih jurusan

Untuk variabel minat diperoleh nilai $\mathrm{t}$ hitung sebesar $10,533 \geq \mathrm{t}$ tabel sebesar 1.65622 dengan nilai signifikan $0,000 .<0,05$ berarti $\mathrm{H}_{1}$ diterima $\mathrm{H}_{0}$ ditolak dengan demikian dapat dikatakan bahwa terdapat pengaruh yang signifikan antara minat terhadap keputusan siswa memilih jurusan

Untuk variabel komunikasi orang tua diperoleh nilai $\mathrm{T}_{\text {hitung }}$ sebesar 5,446 $\geq \mathrm{T}$ tabel sebesar 1.65622 dengan nilai signifikan $0,000 .<0,05$ berarti $\mathrm{H}_{1}$ diterima $\mathrm{H}_{0}$ ditolak dengan demikian dapat dikatakan bahwa terdapat pengaruh yang signifikan antara komunikasi orang tua terhadap keputusan siswa memilih jurusan

Untuk variabel teman sebaya diperoleh nilai $\mathrm{t}$ hitung sebesar $4,300 \geq \mathrm{t}$ tabel sebesar 1.65622 dengan nilai signifikan $0,000<$ 0,05 berarti $\mathrm{H}_{1}$ diterima $\mathrm{H}_{0}$ ditolak dengan 
Vol. 1 No. 2 (Mei 2021) (284-293)

http://ejournal.stkip-pgri-sumbar.ac.id/index.php/horizon

demikian dapat dikatakan bahwa terdapat pengaruh yang signifikan antara teman sebaya terhadap keputusan siswa memilih jurusan.

\section{KESIMPULAN}

Berdasarkan hasil penelitian dan analisis yang telah dilakukan dapat dibuat kesimpulan seperti berikut ini:

\section{Intelegence Quotient (IQ)}

intelegence Quotient (IQ) berpengaruh signifikan terhadap keputusan siswa memilih jurusan. Hal ini dapat dilihat dari hasil nilai koefisien sebesar 0,496. Nilai koefisien ini signifikan karena nilai t hitung $5,792 \geq \mathrm{t}$ tabel sebesar 1.65622 dengan taraf segnifikan sebesar $0,000<0,05$ dan hasil siswa kelas $X$ IPA diperoleh nilai koefisien sebesar 1,074. Nilai koefisien ini signifikan karena nilai $\mathrm{t}$ hitung $14,694 \geq \mathrm{t}$ tabel sebesar 1.67655 dengan taraf signifikan sebesar 0,000>0,05 hasil siswa kelas X IPS diperoleh nilai koefisien sebesar 0,278 Nilai koefisien ini signifikan karena nilai $\mathrm{t}$ hitung $2,410 \geq \mathrm{t}$ tabel sebesar 1.66388 dengan taraf signifikan sebesar 0,018>0,05

\section{Minat}

Minat bepengaruh signifikan terhadap keputusan siswa memilih jurusan. Hal ini dapat dilihat dari hasil nilai koefisien sebesar 0,367. Nilai koefisien ini signifikan karena nilai $\mathrm{t}_{\text {hitung }} 10,533 \geq \mathrm{t}_{\text {tabel }}$ sebesar 1.65622 dengan taraf segnifikan sebesar $0,000<0,05$ dan hasil siswa kelas X IPA diperoleh nilai koefisien sebesar 0,016 Nilai koefisien ini tidak signifikan karena nilai $\mathrm{t}$ hitung $0,311<\mathrm{t}$ tabel sebesar 1.67655 dengan taraf signifikan sebesar $0,742 \leq 0,05$ hasil siswa kelas $\mathrm{X}$ IPS diperoleh nilai koefisien sebesar 0,387. Nilai koefisien ini signifikan karena nilai $\mathrm{t}$ hitung $9,593 \geq \mathrm{t}$ tabel sebesar 1.66388 dengan taraf signifikan sebesar $0,000 \leq 0,05$

\section{Komunikasi Orang Tua}

Komunikasi orang tua bepengaruh signifikan terhadap keputusan siswa memilih jurusan. Hal ini dapat dilihat dari hasil nilai koefisien sebesar 0,309. Nilai koefisien ini signifikan karena nilai $t$ hitung 
$5,446 \geq \mathrm{t}$ tabel sebesar 1.65622 dengan taraf segnifikan sebesar $0,000 \geq 0,05$ dan hasil siswa kelas $\mathrm{X}$ IPA diperoleh nilai koefisien sebesar 0,119. Nilai koefisien ini signifikan karena nilai $\mathrm{t}$ hitung $2,899 \geq \mathrm{t}$ tabel sebesar 1.67655 dengan taraf signifikan sebesar $0,006 \leq 0,05$ hasil siswa kelas X IPS diperoleh nilai koefisien sebesar $0,351 \quad$ Nilai koefisien ini signifikan karena nilai t hitung $4,194 \geq \mathrm{t}$ tabel sebesar 1.66388 dengan taraf signifikan sebesar 0,000 $\leq 0,05$.

\section{Teman Sebaya}

Teman sebaya bepengaruh signifikan terhadap keputusan siswa memilih jurusan. Hal ini dapat dilihat dari hasil nilai koefisien sebesar 0,309. Nilai koefisien ini signifikan karena nilai $\mathrm{t}$ hitung $4,300 \geq \mathrm{t}$ tabel sebesar 1.65622 dengan taraf segnifikan sebesar $0,000 \geq 0,05$ dan hasil siswa kelas X IPA diperoleh nilai koefisien sebesar 0,370. Nilai koefisien ini signifikan karena nilai t hitung $7,053 \geq \mathrm{t}$ tabel sebesar 1.67655 dengan taraf signifikan sebesar $0,000 \leq 0,05$ hasil siswa kelas X IPS diperoleh nilai koefisien sebesar 0,191 Nilai koefisien ini tidak signifikan karena nilai $\mathrm{t}$ hitung $1,862 \geq \mathrm{t}$ tabel sebesar 1.66388 dengan taraf signifikan sebesar $0,000 \leq 0,66$

\section{DAFTAR PUSTAKA}

Ahyuna, A., \& Irmawati, I. (2016). Perancangan Aplikasi Tes IQ Siswa untuk Pertimbangan Pemilihan Jurusan dengan Metode Forward Chaining. Creative Information Technology Journal, Vol.3. No. 2.

Ansofino, dkk. (2016). Ekonometrika. Deepublish.

Arikunto, S. (2010). Prosedur Penelitian Suatu Pendekatan Praktek. Rineka Cipta.

Ghozali, Imam. (2011). Aplikasi Analisis Multivariate dengan Program SPSS 20. badan penerbit universitas diponegoro.

Ghozali, Imam. (2012). Aplikasi Analisis Multivariate Dengan Program IBM SPSS 20. Badan Penerbit Universitas Diponegoro.

Irianto, A. (2010). Statistik ( Konsep Dasar, Aplikasi, dan Pengembangan). 
martha Amelia fadjrin, 2017. (2017).

Pengaruh Lokasi Sekolah, Promosi Sekolah, Persepsi Dan Teman Sebaya Terhadap Minat Siswa Memilih Jurusan.Economic Education Analysis Journal, Vol 6. No.2.

Siregar, S. (2013). Statistika Parametrik Untuk Penelitian Kuantitatif: dilengkapi dengan Perhitungan Manual dan Aplikasi SPSS 17. Rienika Cipta.

Sugiyono. (2012). Doc5.pdf. In Metode Penelitian Manajemen. Alfabeta.

Suharsimi, A. (2006). Doc2.pdf. In prosedur Penelitian suatu Pendekatan Praktek (Renika Cip). 